\title{
An infiltration model development and evaluation for pitcher irrigation system
}

\author{
${ }^{1} \mathrm{H}$ Usman*, ${ }^{1} \mathrm{H}$ Yakubu and ${ }^{2} \mathrm{I} \mathrm{J}$ Tekwa ${ }^{* *}$ \\ ${ }^{1}$ Department of Soil Science, University of Maiduguri, Maiduguri, Borno state, Nigeria. \\ ${ }^{2}$ Department of Agricultural Technology, Federal Polytechnic, P.M.B 35, Mubi, Adamawa \\ State, Nigeria. \\ ${ }^{*}$ Deceased, ${ }^{* *}$ Corresponding Author's e-mail: johntekwa@gmail.com \\ ABSTRACT
}

Infiltration models are based on quantitative relationships among variables that are developed analytically, or from a spectrum of infiltration data that could be fitted into the equation. An attempt was made to begin the development of a mathematical (infiltration)m model using the assumptions of Hillel and Gardner (1969; 1970), incorporating the assumptions of Green and Ampt (1911) and Philip (1957a; 1957c). The model developed in this study used Pitcher (pot) and soil properties, as well as the time of infiltration as inputs. The model proved to be capable of predicting infiltration better than the pitcher infiltration equation advanced by Clifthill (1983), which did not consider the properties of the soil beneath the pitcher. The developed pitcher model gave a better prediction of infiltration, especially with pitchers fired at low temperatures $\left(<650^{\circ} \mathrm{C}\right)$ and, which invariably had higher seepage rates than in pitchers fired at high temperatures $\left(>850^{\circ} \mathrm{C}\right)$.

Keywords: Infiltration model, development and evaluation, pot-firing, temperature, pitcher irrigation

\section{INTRODUCTION}

Soil Water (Infiltration) Model: There exist ample studies for the evaluation of infiltration models either for the purpose of validation or establishment of the model parameters for different soils or for comparing model efficiencies and applicability for various soil conditions (Batch et al, 1986; Topaloglu, 1999; Mudiare and Adewumi, 2000; Haws et al, 2004). The principle of modeling that governs infiltration of water from pitcher irrigation source are similar to those used to model infiltration with other irrigation methods, but there are two major differences. According to Usman (1986), the first difference is concerned with the geometry of the source (pot and soil), and the second involves the frequency of irrigation. Water is usually applied to the entire surface in surface and sprinkler irrigations, so it infiltrates vertically with negligible horizontal movement. In contrast, pitcher irrigation involves either a point or a line source and so only part of the total soil surface is wetted and water moves both vertically and horizontally in the soil (Silva et al, 1984; Stein, 1988).

Infiltration from pitcher (pot) source is a complex process. It is transient and multi-dimensional in nature. According to Usman (1986) and Stein (1998), if the pot source is a single point, a three-dimensional analysis is required, but if the numbers of point sources are close enough, the result will be a strip or a line source, and the analysis will be reduced to two dimensions.

In recent years, several attempts have been made to describe infiltration from point and line sources and arrive at some mathematical model. Such models for pitcher irrigation are not available in the literature. Three categories attempts to describe these approaches: namely; empirical, derived from experimental results; analytical and numerical, which are solutions to Richard's moisture flow equation were subject to certain assumptions (Usman, 1986).

Empirical Equations: These are quantitative relationships among variables without looking into the matter and understanding that clearly show the fundamental operation of the system. Empirical models are usually developed from one of the common empirical equations such as Green-Ampt (1911), Philip (1957b), Kostiakov (1932), Horton (1940) (as listed in Table 1), Talsma and Parlange (1972) and Rao et al (2006), to describe the infiltration process. The final formulation of the empirical model requires a broad spectrum of infiltration data that can be fitted into one or more of these equations. 
In this study, empirical models have been selected because they are generally simple to apply, though tend to be generally restricted in their application in terms of the crops, soil and the environment in which the models were developed and tested, and so have limited application. However, the model could provide useful data for the validation of more generalized models.

Table 1: Empirical Infiltration Equations

\begin{tabular}{|l|l|l|}
\hline Name & Equation & Reference $\left(^{*}\right)$ \\
\hline Green-Ampt & $\mathrm{I}=\mathrm{Kt}(\mathrm{H}+\mathrm{SI}+\mathrm{Z}) \mathrm{Z}$ & Green \& Ampt \\
Kostiakov & $\mathrm{I}=\mathrm{Cit}^{-\mathrm{c}}$ & $(1911)$ \\
Horton & $\mathrm{I}=11+(12-11) \mathrm{e}^{-\mathrm{bt}}$ & Kostiakov (1932) \\
Philip & $\mathrm{I}=\mathrm{Ss} / 2 \mathrm{t}^{1 / 2}+\mathrm{Cl}$ & Horton (1940) \\
Holton & $\mathrm{I}=\mathrm{a}(\mathrm{st}-\mathrm{Fe})^{\mathrm{n}}+11$ & Philip (1957a) \\
& & Holton et al (1967) \\
\hline
\end{tabular}

Where:

I = infiltration rate

$T=$ time after infiltration starts

$\mathrm{Kt}=$ hydraulic conductivity of transmission zone

$\mathrm{H}=$ pressure head at the surface to the wetting front

$\mathrm{Z}=$ distance from the surface to the wetting front

$\mathrm{C}, \mathrm{Cl}, \mathrm{C} 2$ = constant depending on the soil and the initial condition

11 = final (constant) infiltration rate

$12=$ infiltration capacity at $\mathrm{t}=0$

$\mathrm{B}=$ soil parameter which controls the rate of decrease of infiltration rate

$\mathrm{S} 1=$ effective suction at the wetting front

Ss $=$ sorptivity

$\mathrm{Cl}=\mathrm{K} / 3$ or $\mathrm{Cl}=\mathrm{I1}$

$\mathrm{Fc}=$ cumulative infiltration

St $=$ storage potential of the soil

$\mathrm{A}, \mathrm{n}=$ constants depending on soil type

$\left(^{*}\right)=$ references cited by Usman (1986)

\section{MATERIALS AND METHODS}

Pitcher Infiltration Prediction Model Development: The model developed by Hillel and Gardner (1969, 1970) was selected for modification as it fits the conditions under pitcher irrigation. This model incorporates the Green and Ampt (1911) assumption and those of Philip (1957a) which has parameters of similar physical significances. The derivation of the infiltration model is as follows:
Assume an infiltration in steady state condition: the flux through the pot wall, $q_{w}$ will be equal to the flux through the soil $\mathrm{q}_{\mathrm{u}}$ : i.e.

$\mathrm{Q}_{\mathrm{w}}=\mathrm{q}_{\mathrm{u}}$

Or, $\mathrm{K}_{\mathrm{w}}(\mathrm{dH} / \mathrm{dZ})_{\mathrm{w}}=\mathrm{K}_{\mathrm{u}}(\mathrm{dH} / \mathrm{dZ})_{\mathrm{u}}$

Where:

$Q_{w}=$ Water flux through the pot wall

$\mathrm{q}_{\mathrm{w}}$ Water flux through the soil

$\mathrm{K}_{\mathrm{u}}$ = hydraulic conductivity of the soil

$\mathrm{K}_{\mathrm{w}}=$ hydraulic conductivity of the wall, $\mathrm{cm} /$ day

$(\mathrm{dH} / \mathrm{dZ})=$ hydraulic head gradient wall, $\mathrm{cm} /$ day

$(\mathrm{dH} / \mathrm{dZ})_{\mathrm{u}}=$ hydraulic head gradient of the soil, $\mathrm{cm}$

As the suction gradient decreases with increase in wetting depth, the gradient through the soil tends to unity. When final infiltration is approached, the gravitational gradient becomes the only effective force for water with no suction head in the soil below the pot and with the internal pot surface as our reference level, we obtained:

$\mathrm{Q}=\mathrm{K}_{\mathrm{u}}\left(\Psi_{\mathrm{u}}\right)=\mathrm{K}_{\mathrm{w}}\left(\left(\mathrm{H}_{\mathrm{o}}+\Psi_{\mathrm{u}}+\mathrm{Z}_{\mathrm{w}}\right) /\left(\mathrm{Z}_{\mathrm{w}}\right)\right)$

Where:

$\mathrm{K}_{\mathrm{u}}\left(\Psi_{\mathrm{u}}\right)=$ unsaturated hydraulic conductivity of the soil

$\psi_{\mathrm{u}}=\mathrm{a}$ function of the suction head which develops in the soil

$\mathrm{H}_{0}=$ positive hydraulic head imposed on the surface by the water in the pot, and $Z_{w}=$ thickness of the pot wall

If, water ponding depth is negligible and pot wall is thin and of low conductivity (e.g. where $Z_{w}$ is very small in relation to the suction, $\psi_{\mathrm{u}}$, which forms at the pot-soil interface), we assume the following approximation.

$Q_{w}=q_{u}=K_{w}\left(\psi_{u} / Z_{w}\right)$

Where:

The condition that the pot wall remain saturated even while its lower part will be under suction is that its critical air-entry was not exceeded (i.e. $\psi_{\mathrm{u}}<\psi_{\mathrm{a}}$ ). This yield:

$\mathrm{K}_{\mathrm{u}} / \mathrm{Z}_{\mathrm{u}}=\mathrm{K}_{\mathrm{w}} / \mathrm{Z}_{\mathrm{w}}=\mathrm{I} / \mathrm{R}_{\mathrm{w}}$.

i.e. the ratio of hydraulic conductivity of the soil to its suction is approximately equal to the ration of the pot's saturated hydraulic conductivity to its thickness, where:

$\mathrm{R}_{\mathrm{w}}=$ hydraulic resistance per unit area of the pot wall, also by equation (2) we obtain: 
$\mathrm{q}=\mathrm{K}_{\mathrm{u}}\left(\psi_{\mathrm{u}}\right)=\psi_{\mathrm{u}} / \mathrm{R}_{\mathrm{w}}$

Employing 'a K vs. $n$ ', relationship of the type $K$ an ${ }^{-0.5}$ (where 'a' and ' $n$ ' are

characteristic constants of the soil) the following can be obtained:

$q=\left(a^{*} l /(n+1) /\left(R_{w} n(n+l)=B / R_{w}{ }^{n}(n+l) \ldots \ldots \ldots\right.\right.$. Eq. (5)

$\Psi_{\mathrm{u}}=\left(\mathrm{aR}_{\mathrm{w}}\right) 1 /(\mathrm{n}+1)=\mathrm{BR}_{\mathrm{w}} 1(\mathrm{n}+\mathrm{l})$

(6)

Where; $B=$ a $1 /(n+1)$

Note that both pot wall and the soil around it are seen to affect the infiltration rate and suction profile. The pot wall is thus, viewed as a self-adjusting system in which physical properties of the pot wall and underlying soil interact in time to form a steady infiltration rate and moisture profile. The soil suction beneath the pot creates a gradient through the pot wall and conductivity in the soil below it, which will result in an equal flux through both layers.

In the case of transient infiltration into an initially unsaturated profile, during which the flux, the wetting depth, the soil suction under the pot, and the conductivity might all be changing with time, the problem becomes more complicated.

Assuming the Green and Ampt conditions:

- That there exists a distinct and precisely definable wetting front.

- The matric suction of the wetting front remains effectively constant, regardless of time and position.

- Also, assume that, behind the wetting front, the soil is uniformly wet and of constant conductivity, and

- That the wetting front is thus, viewed as a plane separating a uniformly wetted infiltrated zone from totally un-infiltrated zone.

In effect, this supposes the ' $K$ vs. q' relation to be discontinuous, (i.e. change abruptly, at the suction value prevailing at the wetting front).

In addition, with Ho negligible, three stages during transient infiltration into the wall of the pot can be recognized;

1) An initial stage, in which the rate is finite and dependent on pot wall resistance, $R_{w}$, and on effective subsoil suction;
An intermediate stage, in which cumulative infiltration, 'I' decreases approximately as the square root of time; and

3) A later stage, in which, 'l' can be expressed as the sum of a steady and transient term, the later becoming negligible at long times. 'l' decreases with increasing $R_{w}$, particularly in less permeable pot walls.

Infiltration through the pot wall can be decreased by the approximation that water enters into the soil below, at nearly constant suction. Pot wall resistance and hydraulic characteristics of the soil determine the magnitude of the infiltration, where the gravity effect is negligible (i.e. in horizontal flow, during initial stages of vertical infiltration into an initially dry medium of high matric suction). The infiltration vs. time relationship was given by:

$\mathrm{I}=\left[\mathrm{K}_{\mathrm{u}}{ }^{2} \mathrm{R}_{\mathrm{w}}{ }^{2}(\Delta \theta)^{2}+2 \mathrm{~K}_{\mathrm{u}} \mathrm{H}_{\mathrm{f}} \Delta \theta \mathrm{t}\right]^{0.5}-\mathrm{K}_{\mathrm{u}} \mathrm{R}_{\mathrm{w}} \ldots \ldots$. Eq. (7)

Where:

$\mathrm{I}=$ cumulative infiltration (in $\mathrm{ml}$ or $\mathrm{cm}$ )

$\mathrm{K}_{\mathrm{u}}=$ hydraulic conductivity of the soil ( $\mathrm{cm} /$ day)

$\mathrm{R}_{\mathrm{w}}=$ hydraulic resistance of the pot wall

$\mathrm{H}_{\mathrm{f}}=$ suction force in the transmission zone, negative head of water, $\mathrm{cm}$

$\Delta \theta=$ change in water content $(\%)$

$\mathrm{T}=$ time (days or hours or minutes)

Where the gravity effect is significant, the expression given is;

$\left.\left.L_{f}=K_{u} t / \Delta \theta+\left(H_{f}-K_{u} R_{w}\right) \ln \left(K_{u} t+\Delta \theta\right)+t\right)\right] / H_{f} \quad E q$. (8)

Where the correction term ' $t$ ' becomes negligible, the ' $t$ ' term increases, thus, $L_{f}$ can be expressed as the sum of a steady and transient term.

\section{RESULTS}

The Pitcher Infiltration Model: The model selected as being the most appropriate for the purpose of this project is that of Hillel and Gardner (1969, 1970), based on Green and Ampt (1911) assumptions and those of Philips (1957a), because of the similarity in physical processes to those of pitcher irrigations. However, the model of Hillel and Gardner (1969, 1970) differs in some details, in which water is ponded on the soil surface against into the pots in pitcher irrigation.

The selection of the most appropriate model and its development were based on the following assumptions: 
i) The soil and pot stable, the soil is isotropic and homogeneous, and its properties do not change with and does not shrink or swell with change in soil water content.

ii) The hydraulic properties (hydraulic conductivities of the pot and soils) are, each single value, unique and continuous function of water content and tension of soil or plant as well as the pots, thus hysteretic effect assumed negligible.

iii) The hydraulic conductivity water content relationship changes abruptly, at suction values prevailing at the wetting front.

iv) The soil more permeable than pot wall and water moves from the pot into the soil below at nearly constant suction; the magnitude of which is determined by the resistance of the wall of the pot and hydraulic characteristics of the soil.

Assuming that gravity is negligible, the Pitcher infiltration equation (7) becomes the model and can be used as follows:

$\mathrm{I}=\left[\mathrm{K}_{\mathrm{u}}{ }^{2} \mathrm{R}_{\mathrm{w}}{ }^{2}(\Delta \theta)^{2}+2 \mathrm{~K}_{\mathrm{u}} \mathrm{H}_{\mathrm{f}} \Delta \theta \mathrm{t}\right]^{0.5}-\mathrm{K}_{\mathrm{u}} \mathrm{R}_{\mathrm{w}}$

where:

$\mathrm{I}=$ cumulative infiltration $(\mathrm{cm})$

$\mathrm{K}_{\mathrm{u}}=$ hydraulic conductivity of the soil (cm/day)

$\mathrm{Rw}=$ hydraulic resistance of the pot wall

$\mathrm{H}_{\mathrm{f}}=$ suction force in the transmission zone, negative

head of water, $\mathrm{cm}$

$\Delta \theta=$ change in water content $(\%)$

$\mathrm{t}=$ time (day)

Equation (7) above can be expressed as:

$$
\mathrm{I}=[\mathrm{a}+\mathrm{b}] 0.5-\mathrm{cx}
$$

Where:

$a=$ function of hydraulic resistance of the wall of the pot, conductivity of the soil and change in water content of the soil, that is: $\mathrm{a}=\mathrm{K}_{\mathrm{u}}{ }^{2} \mathrm{R}_{\mathrm{w}}{ }^{2}(\Delta \theta)^{2}$

$b=a$ function of hydraulic conductivity of the soil, change in water content and time, as:

$\mathrm{b}=2 \mathrm{~K}_{\mathrm{u}} \Delta \theta$, and $\mathrm{c} \& \mathrm{x}=$ hydraulic conductivity of the soil resistance of the pot wall,

respectively, as $c x=K_{u} R_{w}$

The equation can finally be simplified to:

$\mathrm{I}=(\mathrm{a}+\mathrm{b})^{0.5}-\mathrm{cx}$

An example of the input parameters for the Pitcher infiltration model is given in Table 2 .
Table 2: Input parameters for are computation of pitcher equation infiltration model

\begin{tabular}{|l|l|}
\hline S/No & INPUT DATA PARAMETERS \\
\hline 1 & $\mathrm{~K}_{\mathrm{u}}=$ hydraulic conductivity of the soil $(\mathrm{cm} /$ day $)$ \\
3 & $\mathrm{R}_{\mathrm{w}}=$ hydraulic resistance of the pot wall \\
4 & $\begin{array}{l}\mathrm{H}_{\mathrm{f}}=\text { suction force in the transmission zone, } \\
\text { negative head of water, } \mathrm{cm}\end{array}$ \\
5 & $\mathrm{t}=$ time infiltration, days \\
6 & $\mathrm{I}=$ cumulative infiltration $(\mathrm{cm})$ \\
\hline
\end{tabular}

Example of Pitcher infiltration model calculation using Table 2 which shows the input parameters used in the model calculation:

The model is

$\mathrm{I}=\left[\mathrm{K}_{\mathrm{u}} \mathrm{R}_{\mathrm{w}}{ }^{2}(\Delta \theta)^{2}+2 \mathrm{~K}_{\mathrm{u}} \mathrm{H}_{\mathrm{f}} \Delta \theta\right]^{0.5}-\mathrm{KuR}_{\mathrm{w}}$ $=(a+b)^{0.5}-c x$

Given:

$\mathrm{K}_{\mathrm{u}}+2.01 \mathrm{~cm} /$ day, $\mathrm{R}_{\mathrm{w}}=3.98, \theta \mathrm{V}=0.06, \mathrm{H}_{\mathrm{f}}=136 \mathrm{~cm}$, $\mathrm{t}=34$ days, and

$\mathrm{I}=(\mathrm{a}+\mathrm{b})^{0.5}-\mathrm{cX}$

Also, where

$\mathrm{a}=\mathrm{K}_{\mathrm{u}}^{2} \mathrm{R}_{\mathrm{w}}(\Delta \theta)^{2}$

$\mathrm{b}=2 \mathrm{~K}_{\mathrm{u}} \mathrm{H}_{\mathrm{f}} \Delta \theta \mathrm{t}$,

$\mathrm{c}=\mathrm{K}_{\mathrm{u}}$ and

$x=R_{w}$

then, submitting the values in the equation, we have

$a=2.01^{2 *} 3.98^{*} 0.062=0.230$

$b=2 * 2.01 * \mid 36^{*} 0.06 * 34=1115.3$

$c=2.01$

$x=3.98$

Therefore, cumulative infiltration, 'l' equals,

$I=(0.230+1115.3)^{0.5}-2.01 * 3.98$

$\mathrm{I}=25.4 \mathrm{~cm}$

i.e. $25.4 \mathrm{~cm}$ of water was lost in 34 days of infiltration. This is equivalent to $25 / 34 \mathrm{~cm} /$ day, which is equal to $0.747 \mathrm{~cm} /$ day or $7.47 \mathrm{~mm} /$ day infiltration rate

Model Validation: The model validation was done using data obtained from a study involving ten pitchers (pots) (A1 - A10), treated with $400 \mathrm{~cm}$ saw dust added to grey or red-colored clay, and with five different electric Kiln-firing temperatures for the pitchers. The treatment included;

$\mathrm{Al}=$ Red clay $+400 \mathrm{~cm}^{3}$ at Pitcher Kiln firing temperature of $650^{\circ} \mathrm{C}$ 
A2 = Grey clay $+400 \mathrm{~cm}^{3}$ at Pitcher Kiln firing temperature of $650^{\circ} \mathrm{C}$

$\mathrm{A} 3=$ Red clay $+400 \mathrm{~cm}^{3}$ at Pitcher Kiln firing temperature of $750^{\circ} \mathrm{C}$

A4 = Grey clay $+400 \mathrm{~cm} 3$ at Pitcher Kiln firing temperature of $750^{\circ} \mathrm{C}$

A5 = Red clay $+400 \mathrm{~cm} 3$ at Pitcher Kiln firing temperature of $850^{\circ} \mathrm{C}$

A6 = Grey clay $+400 \mathrm{~cm}^{3}$ at Pitcher Kiln firing temperature of $850^{\circ} \mathrm{C}$

A7 = Red clay $+400 \mathrm{~cm}^{3}$ at Pitcher Kiln firing temperature of $950^{\circ} \mathrm{C}$

A8 = Grey clay $+400 \mathrm{~cm}^{3}$ at Pitcher Kiln firing temperature of $950^{\circ} \mathrm{C}$

A9 = Red clay $+400 \mathrm{~cm}^{3}$ at Pitcher Kiln firing temperature of $1150^{\circ} \mathrm{C}$

A10 = Grey clay $+400 \mathrm{~cm}^{3}$ at Pitcher Kiln firing temperature of $1150^{\circ} \mathrm{C}$.

Each of the pitchers was buried in the ground with its neck sticking out. Water was applied to the pitchers daily and seepage rates calculated for thirty four days. Mean seepage rate (Pitcher infiltration rate) was used for validation of the Pitcher irrigation model developed.

\section{DISCUSSION}

Fitting the Infiltration Model: The model was validated with the infiltration equation used by Clifthill (1985), described as:

$$
I=\frac{[10(\text { mean seepage of pots })(\mathrm{ml} / \text { day }) 1}{\left[\text { Estimated pot surface area }\left(\mathrm{cm}^{2}\right)\right]}
$$

The Pitcher infiltration model is given as:

$\mathrm{I}=\left[\mathrm{K}_{\mathrm{u}}^{2} \mathrm{R}_{\mathrm{w}}{ }^{2}(\Delta \theta)^{2}+2 \mathrm{~K}_{\mathrm{u}} \mathrm{H}_{\mathrm{f}} \Delta \theta \mathrm{t}\right]^{0.5}-\mathrm{K}_{\mathrm{u}} \mathrm{R}_{\mathrm{w}}$

$=(a+b) 0.5-c x$

Where model temperatures are as described in equation (7).

To find the models that best fit the measured data from field measurement with minimum deviations, the procedure of least squares as presented in Statistix ver. 8.0, which is a criterion of goodness of fit, was used. The best-fitted line minimizes the sum of squares of the deviations of the observed values of the pitcher infiltration rate from those predicted (Usman, 2006).
There was a significant difference $(P<0.01)$ between the infiltration rates of the measured and the two models. Figure 1 show that the pitcher infiltration model developed gave higher values (38.0 - 69.0\%) for pitchers (Al - A6) fired at $>850^{\circ} \mathrm{C}$ than those obtained by the Clifthill (1985) model. Also, all the models showed decreasing infiltration rates as the Pitcher firing temperature increased $\left(650-1150^{\circ} \mathrm{C}\right)$.

The mean infiltration rate for the ten Pitchers measured was $2.9 \mathrm{~mm} /$ day with a coefficient of variation (CV) of $51 \%$ (Fig. 1). The mean predicted infiltration rake by the Clifthill (1985) model was 2.21 $\mathrm{mm} /$ day with a CV of $50.01 \%$ (Table 3 ). Electric firing kiln temperatures for the pitchers have been reported to increase pitcher vitrification, thus making those fired at high temperatures to have lower pot-wall porosity (Usman, 1986). It implies that infiltration variability was expected with the wide range of pitcher temperatures used.

Table 3: Estimated Infiltration rates and residual mean square errors of regression for Pitcher irrigation model and Cliflhill (1985) Pitcher

\begin{tabular}{|c|c|c|c|c|c|c|}
\hline \multirow{3}{*}{ Treatment } & \multicolumn{4}{|c|}{ Infiltration rates of the Models } & & \\
\hline & Pitcher & & Clifthill & & \multicolumn{2}{|l|}{$\begin{array}{l}\text { Squa. } \\
\text { RMSE) }\end{array}$} \\
\hline & $\begin{array}{l}1 \\
(\mathrm{~mm} / \mathrm{d})\end{array}$ & $\mathrm{R}^{2}$ & & $\mathrm{R}^{2}$ & Pitcher & Clifthill \\
\hline $\bar{A} 1$ & 4.12 & 0.98 & 3.37 & 0.98 & 0.62 & 0.64 \\
\hline A2 & 4.12 & 0.98 & 3.33 & 0.98 & 0.85 & 0.86 \\
\hline A3 & 4.01 & 0.98 & 3.28 & 0.98 & 0.18 & 0.19 \\
\hline A4 & 3.33 & 0.98 & 2.97 & 0.98 & 0.69 & 0.71 \\
\hline A5 & 2.26 & 0.98 & 2.21 & 0.98 & 0.68 & 0.68 \\
\hline A6 & 2.01 & 0.98 & 1.98 & 0.98 & 1.03 & 1.04 \\
\hline A7 & 1.32 & 0.98 & 1.34 & 0.98 & 1.58 & 1.59 \\
\hline A8 & 1.31 & 0.98 & 1.23 & 0.98 & 2.01 & 2.03 \\
\hline A9 & 1.31 & 0.98 & 1.21 & 0.98 & 2.11 & 2.11 \\
\hline A10 & 1.31 & 0.98 & 1.22 & 0.98 & 1.94 & 1.96 \\
\hline Mean & 2.51 & 0.98 & 2.21 & 0.98 & 1.17 & 1.18 \\
\hline SD & 1.25 & & 0.94 & & & \\
\hline CV (\%) & 50.01 & & 42.78 & & & \\
\hline
\end{tabular}
Infiltration equation. 


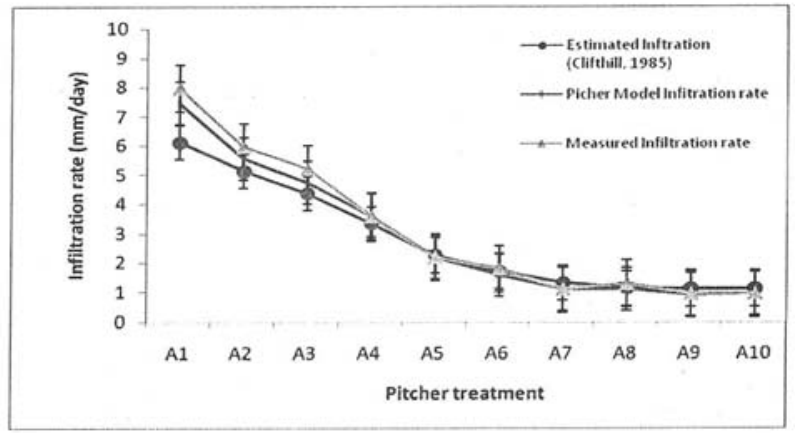

Fig 1: Comparison of measured, Clifthill (1985) estimated infiltration and Pitcher irrigation model predicted infiltration rates. $I=$ Standard error, $(P<$ $0.01, R^{2}=0.954, n=30$ ).

Results from linear regression of measured and predicted Pitcher infiltration rates by Clifthill (1985) model and the Pitcher infiltration model (Figure 2) both showed $R^{2}$ value (0.998) which is close to unity, indicating good agreement between the measured and predicted values. Linear regression revealed that fitting the Pitcher model (RMSE = 1.36) and Clifthill (1985) model (RMSE $=1.39)$ gave low residual root mean square deviation from the mean (RMSE) (Table 3). The lower RMSE value for the Pitcher infiltration model implies that it fitted the model better than that of the Clifihill (1985) model. Similarly, the chi-square of goodness fit test revealed that the difference between the measured and the predicted infiltration values by the Pitcher infiltration model (0.244) and Clifthill (1985) model (0.293) was not significantly different $(P>0.05)$, indicating that the two models tested, fit the data fairly well. Therefore, both equations can be used to predict infiltration rates of pitchers into the soil.

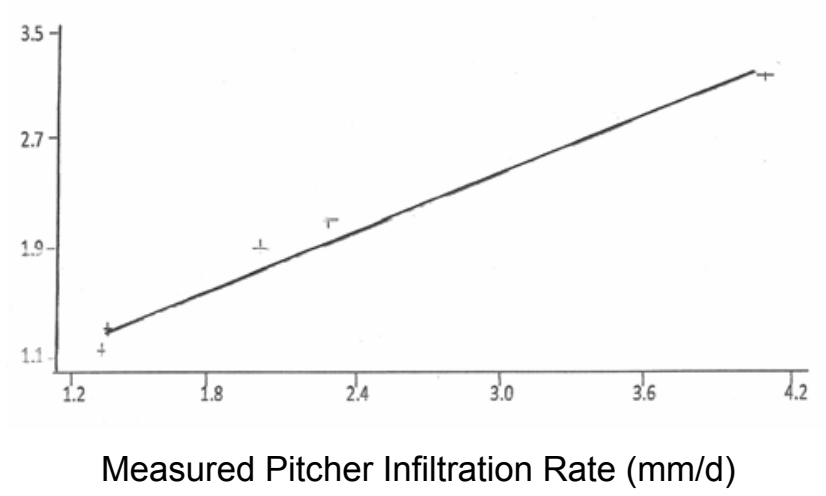

Fig. 2: Regression line of measured and predicted infiltration Rate by Pitcher model
The procedures of nonlinear least-squares was employed to predict the infiltration rate and $R$ values obtained for both models was near unity $(>0.98)$ (Table 3), therefore fits the data well. This result confirms the results of the RMSE and indicates that the Pitcher infiltration model can adequately predict infiltration rates under Pitchers, in agreement with results of Usman (1986: 2006) which also followed the procedure of linear least -square fit.

Finally, to obtain the best fit model, the Pitcher irrigation model gave three normal iterative cycles while Clifthill (1985) model gave five cycles, implying that the Pitcher model best fitted the infiltration data and was more superior to the model of Clifthill (1985) model.

From the foregoing, results show that at lower pitcher firing temperature, Clifthill (1985) model underpredicted the infiltration rate by $38.0-69.9 \%$ while at higher firing temperatures, this difference had reduced to $<4.0 \%$. One explanation for the differences could be attributable to the differences in the parameters of the two equations or models used (Usman, 1986).

Results from this study corroborates those of Clifthill (1985), who reported that pitcher seepage rates increased with decreasing Pitcher firing temperatures $\left(<850^{\circ} \mathrm{C}\right)$ and assumed that African pots (because they might have been fired at lower temperature) had higher seepage rates than British pots fired at $>850^{\circ} \mathrm{C}$. This implies that Clifthill (1985) infiltration equation would have predicted better if adjusted to the condition of the soil beneath the pitcher, as in the presently developed pitcher infiltration model.

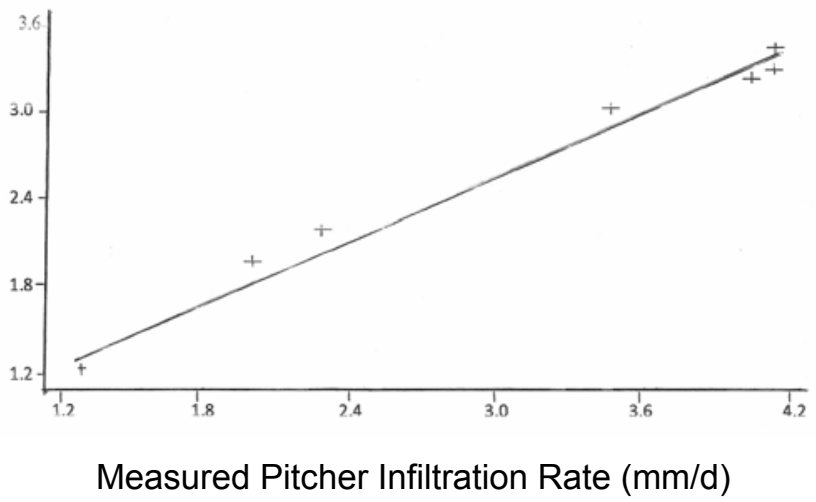

Fig. 3: Regression line of measured and predicted infiltration Rate by Clifthill mode 


\section{CONCLUSIONS}

While the infiltration model in the present study considered the pot wall, the equation used by Clifthill (1985) did not. In addition to using the pot wall thickness, the pitcher infiltration model also uses the hydraulic conductivity of the pot wall and soil, the water content of the soil, soil matric suction and the time water takes to infiltration into the soil, which Clifthill (1985) did not use.

On the other hand, the equation used by Clifthill (1985) only used the surface area of the pot and the mean seepage rates of the pots, which the present infiltration model also additionally used. The reliability of the model's result can be supported by the experimental findings that wetted soil volume only depends on the total volume of water applied and on the mean seepage rates of the pitchers (Usman, 1986). Note that the presences of the pot wall impede (delay) water infiltration into the soil, ensuring that the soil was wetted uniformly. Again, since pot seepage was found to depend on the conductivity of the pot wall and soil water suction, ignoring these parameters will lead to gross inaccuracies in predicting infiltration rate of the pots. The model is therefore a more reliable predictor of infiltration from the pots to the soil because it considers both the pot and soil parameters.

The model was developed in a sandy loam soil with vegetable crops, for which simulation may be restricted therefore; other crops and soil types need to be tested to obtain optimum soil water between the pitchers (pots) for the various design parameters.

\section{REFERENCES}

Alemi, M. H., 1981. Distribution of water and salt in soil under Trickle and Pot irrigation regimes. Agricultural Water Management, Vol. 3, pp. 195-203.

Bach, I. B., Wierenga, P. J. And Ward, T. J., 1986. Estimation of the Philip infiltration parameters from rainfall simulation data. Soil Science Society of America Journal, Vol. 50: 1319-1323.
Clifthill, A., 1985. Investigation of design requirements, operation and performance of Pitcher irrigation. Unpublished M.Sc. Thesis, Silsoe College, England.

Green, W.H. and Ampt, G.A., 1911. Studies on Soil Physics. Journal of Agricultural Science, 4: 1-24.

Haws, N.W., Liu, B., Boast, C. W. Rao, P. S. C., Kladivko, E.J. and Franzmeier, D.P., 2004. Spatial variability and measurement scale of infiltration rate on an agricultural landscape. Soil Science Society of America Journal, 68: 1818-1824.

Hillel, D. and Gardner, W.R., 1969. Steady infiltration into crust-topped profiles. Soil Science, 108:137-142.

Mudiare, 0. J. and Adewumi, J.K., 2000. Estimation of infiltration from field-measured sorptivity values. Nigerian Journal of Soil Research, 1: 1-3.

Silva, A. de S., Silva, D.A., Gheyi, H.R. and Porto, E. R., 1984. Viability of porouscapsule irrigation in semi-arid regions, Persquinsa Agropecuaria Brasileria, 19(10): 1257-1265.

Stein. T.M., 1998. Eraarbeitung and Uberprufung Bon Entwurfskriterien Fur Gefabbewasseerungsanlagen (Development and evaluation of design criteria for pitcher irrigation systems, translation of original title). Der Trupenlandwirte (English summary).

Philip, J. R., 1957a. An infiltration equation with physical significance. Soil Science, 77, 153-157.

Philip, J. R., 1957b. The theory of infiltration: 1. The infiltration equation and its solution. Soil Science, 83: 345-357.

Philip, J. R., 1957c. The theory of infiltration: 4. Sorptivity and algebraic infiltration equations. Soil Science, 84: 257-264.

Topaluglu, F., 1999. Comparing tillage technique by using a new infiltration method. Tropical Journal of Agriculture and Forestry, 23: 609-614.

Usman, H., 1986. Effects of improving clay pot design on moisture distribution in Pitcher irrigation. Unpublished M.Sc. Thesis, Silsoe College, Silsoe, England.

Usman, H. and Chinade, A., 2006. Effects of Pitcher irrigation on the performance of three vegetable at Maiduguri, Nigeria. Journal of Tropical Agriculture, 8: 201-214. 